\author{
Chris Cooper \\ Oxford Brookes University, UK \\ UDC 338.482:303.4 \\ 005.94:338.48
}

\title{
THE IMPERATIVE OF KNOWLEDGE EXCHANGE FOR TOURISM EDUCATORS
}

\section{The Issue}

There is significant gap between tourism educators/researchers and the tourism sector itself. Quite simply the tourism sector does not engage with tourism educators or researchers: indeed the sector could be seen as a research-averse (Cooper and Ruhanen 2002). This gap between tourism knowledge generation and its utilization is not new (Hudson 2013; Pyo 2012; Thomas 2012; Tribe 2008). It is however, an important issue for tourism as it is also clear that the generation and use of new tourism knowledge for innovation and product development is critical for the competitiveness of both the tourism sector and destinations. This paper argues that tourism educators must understand how to exchange their knowledge with the sector to deliver competitiveness and sustainability.

Shaw and Williams (2009) argue that tourism educators and researchers came late to the notion of knowledge exchange due to the dominance of small firms in tourism and the decoupling of tourism research from mainstream social science research. Hudson (2013) confirms the issue of poor linkages between the two groups and goes on to argue that tourism knowledge production systems are too academic and fail to codify knowledge to be used by practitioners which at best has led to the inefficient use of research.
Whilst this goes some way to explaining the poor record of knowledge exchange in tourism, it can also be argued that the very nature of the tourism sector itself is an issue, with many of the prior conditions necessary for the successful exchange and adoption of knowledge absent. The sector is characterized by:

- A dominance of small enterprises, often single person or family owned, lacking managerial expertise or training. They therefore take a singularly instrumental view about knowledge; it must be highly relevant to their operation if they are to adopt and use it;

- Delivery of the tourism product is fragmented across a variety of providers with a lack of ownership for the total experience and hence poor coordination for knowledge exchange and adoption across the sector;

- Vocational reinforcers rooted in poor human resource practices, militate against the continuity of knowledge exchange and adoption. These include the employment of seasonal and part-time workers, high labour turnover and a poorly qualified sector which inhibits absorptive capacity of tourism organizations. It is always difficult to achieve effective knowledge exchange and adoption with employees who have a low commitment to the organization;

- In addition, Weidenfeld et al. (2009) see tourism as a sector characterized by low 
risk takers, a low level of resources for investment, lack of trust and collaboration amongst businesses, and rapid turnover of both businesses and employees.

\section{Knowledge Exchange}

The foundation of knowledge management is based on the effective exchange and use of knowledge to contribute to the competitiveness of both organizations and destinations (Cooper 2006). The knowledge management literature provides insights to understanding the knowledge exchange process. It is clear that to achieve effective knowledge exchange in tourism, knowledge must be understood as the most important commodity and learning the most important process. Of course, knowledge exchange can happen informally through spontaneous or unstructured processes, but knowledge management does not leave it to chance and creates a structured and disciplined approach where the key element is the imperative of transmission plus absorption and a range of tools and activities are employed to make it happen.

\section{Tourism Contexts of Knowledge Exchange}

To successfully exchange knowledge with the sector, educators can envisage a landscape of adoption of innovation and exchange where the whole eco-system of the barriers, gatekeepers and receptors of knowledge and innovation are critical (Cooper et al. 2003). For educators, navigating the landscape depends upon understanding:

- The sources, legitimacy, quality and reliability of knowledge;

- Adopter characteristics and capacity to adopt - in other words the point to which knowledge is exchanged to, and how it is deployed. In tourism, the concept of absorptive capacity is relevant (Cohen and Levinthal 1990);

- The nature of the media used for the exchange must be appropriate to the innovation - in particular the use of 'relational' channels, where it is possible to develop the frequency and depth of twoway human-to-human contact;

- The degree of partner similarity in terms of interests, background, or education;

- The level of depreciation of knowledge after exchange; and

- The level of organizational self-knowledge, the more an organization knows the more receptive it tends to be.

Within tourism, learning by individuals occurs within networks and communities of practice (COPs) - in other words, within a context rather than in isolation, and these contexts play a major role in understanding of knowledge exchange.

\section{Learning networks}

There is no doubt that networks are a fundamental context and medium for the emergence and exchange of information (Myers et al. 2012). Effectively, networks allow members to 'access' knowledge, as well as in some cases actually 'generate' knowledge. Reagans and McEvily (2003) state that network structure impacts fundamentally upon knowledge exchange. They found that over and above the effect of the strength of the tie between two people, knowledge exchange is facilitated by social cohesion amongst network members and network range. Here the concept of both geographic space and network space is useful (Huggins et al., 2012). Here, networks allow access to knowledge firstly, through geographical clustering of organizations in say a destination, and secondly within network space which may be a tourism distribution channel or hotel marketing collective. 
Good governance and management of a network is needed in order to achieve effective knowledge flows within and beyond the network. This will also manage new entrants and ensure that knowledge is not lost to the network's members ( Eickelpasch and Fritsch 2005).

\section{Communities of practice}

To achieve successful knowledge exchange, educators can learn from the concept of COPs. There are many characteristics of COPs that are helpful to knowledge exchange (Gotvassli 2008). Take the descriptors of a COP for example:

- A COP is a group of individuals who develop a shared language and way of working together to accomplish some purposeful activity;

- COPs therefore differ from networks in that they have a purpose and are not just a set of relationships;

- Trust and collaboration are important dimensions of effective COPs.

- COPs increasingly need organizational regulation and management; and

- COPs can be cultivated and leveraged for strategic advantage.

For educators, identifying the relevant tourism COP - say marketing or policy - is important, as well as then identifying those who control and manage knowledge for the COP.

\section{The Way Forward}

This paper has been concerned with the imperative for tourism educators to engage with the concept of knowledge exchange and to understand the tourism contexts within which it takes place. This raises a number of issues for the future if the tourism sector is to benefit from the increased exchange, sharing and exchange of knowledge with educators and researchers (Johannessen at al. 2000). These issues can be summarized as follows:

\section{Policy}

As the knowledge-based economy has developed, governments have been faced with the need to develop policy initiatives. Effectively, these policies grapple with the issues surrounding the nature of knowledge as a global public good. Here it is clear that tourism higher education and research is part of national systems and we are seeing a more utilitarian tone to the bidding for research funds (Thomas 2012), the increasing importance of the research 'impact' agenda and the juggernaut of research selectivity exercises (Hall 2011). This direction of travel should be good news for both tourism researchers and educators who will have to demonstrate the impact of their work to the sector, but the key to success will still be the response of the research users.

\section{Core tourism knowledge and decision-making}

An important task for the future will be evaluating core knowledge for organizations and destinations (Pyo 2012) and as part of this, ensuring that tacit knowledge is effectively captured (Yang and Wan 2003). A related issue relates to assessing the sustainability of tourism knowledge and its application in destinations and organizations - in other words assessing the 'shelf life' of knowledge and beginning to document how decisions are reached.

\section{Learning organizations and destinations}

In terms of knowledge exchange, there is no doubt that destinations can be viewed as a key building block. The imperative for destinations is to become learning or- 
ganizations if they are to be competitive in a time of continuous change. Here there should be an increased emphasis on the 'total knowledge base' emphasizing the fact that knowledge exists external to an organization/destination as well as internally. The future will be therefore be characterized by a widening of the sources of knowledge used by organizations and destinations. In particular, there will be an expanded role for customers, suppliers and partners, including educators, and a greater involvement of external stakeholders in the knowledge management process.

\section{Conclusion}

This leads to two conclusions. Firstly, that by embedding themselves firmly into destinations and the sector's networks and communities of practice, educators and researchers will begin to find that trust is enhanced and that exchange will begin to take place (Hudson 2013). Secondly, knowledge exchange is a discretionary activity, and along with learning, follows the path of least resistance (Reagans and McEvily 2003). The lesson is clear: the knowledge that we generate as educators and researchers must be of true relevance to the sector if it is to be utilized.

\section{References}

Cohen, W. M. and Levinthal, D. A. (1990). Absorptive capacity: a new perspective on learning and innovation. Administrative Science Quarterly 35: 128-152.

Cooper, C. (2006). Knowledge management and tourism. Annals of Tourism Research 33(1): 47-64.

Cooper, C. and Ruhanen, L. (2002). Best Practice in Intellectual Property Commercialization. Brisbane: CRCST.
Cooper, C., Prideaux, B. and Ruhanen, L. (2003). Expanding the Horizons of Tourism Research: Developing a Knowledge Management Approach to Research Funded by the Cooperative Research Center for Sustainable Tourism. CAUTHE Conference proceedings.

Eickelpasch, A. and Fritsch, M. (2005) Contests for cooperation-A new approach in German innovation policy. Research Policy 34: 1269-1282.

Gotvassli, K-A (2008). Community knowledge - a catalyst for innovation.Regional Analysis and Policy 38(2): 145-158.

Hall, C. M. (2011). Publish and perish? Bibliometric analysis, journal ranking and the assessment of research quality in tourism. Tourism Management 32(1): 16-27.

Hudson, S (2013). Knowledge exchange: A destination perspective. Journal of Destination Marketing and Management 2: 129-131.

Huggins, R., Johnston, A. and Thompson, P. (2012). Network capital, social capital and knowledge flow: How the nature of interorganizational networks impacts on innovation. Industry and Innovation 19(3): 203-232.

Johannessen, J., Olaisen, J. and Olsen, B. (2000). Mismanagement of Tacit Knowledge. Available at www.SKIKT.org - Accessed on 3 March 2004.

Myers, S., Zhu, C. and Leskovec, J. (2012). Information diffusion and external influence in networks.In the Proceedings of the 18thACM SIGKDD International Conference on Knowledge Discovery and Data Mining (pp. 33-41). New York: ACM.

Pyo, S. (2012). Identifying and prioritizing destination knowledge needs. Annals of Tourism Research 39(2): 1156-1175.

Reagans, R. and McEvily, B. (2003). Network structure and knowledge exchange: The effects of cohesion and range. Administrative Science Quarterly 48(2): 240-267.

Shaw, G. and Williams, A. M. (2009). Knowledge exchange and management in tour- 
ism organisations: An emerging research agenda. Tourism Management 30: 325335.

Thomas, R. (2012). Business elites, universities and knowledge exchange in tourism. Tourism Management 33: 553-561

Tribe, J. (2008).Tourism: A Critical Business. Journal of Travel Research 46: 245-257.
Weidenfeld, A., Williams, A. M. and Butler, R. W. (2009). Knowledge exchange and innovation among attractions. Annals of Tourism Research 37(3): 604-626.

Yang, J. T., and Wan, C-S (2003). Advancing organizational effectiveness and knowledge management implementation. Tourism Management 25: 593-601. 